Article

\title{
Comparison of Methods for Bed Shear Stress Estimation in Complex Flow Field of Bend
}

\author{
Liyuan Zhang, Faxing Zhang *, Ailing Cai, Zhaoming Song and Shilin Tong
}

State Key Laboratory of Hydraulics and Mountain River Engineering, Sichuan University, Chengdu 610065,China; Zhangliyuan_SCU@163.com (L.Z.); caidouhua_scu@163.com (A.C.); szming970116@163.com (Z.S.); ts1_1996@163.com (S.T.)

* Correspondence: zhfx@scu.edu.cn

Received: 16 August 2020; Accepted: 30 September 2020; Published: 2 October 2020

\begin{abstract}
Bed shear stress is closely related to sediment transport in rivers. Bed shear stress estimation is very difficult, especially for complex flow fields. In this study, complex flow field measurement experiments in a $60^{\circ}$ bend with a groyne were performed. The feasibility and reliability of bed shear stress estimations using the log-law method in a complex flow field were analyzed and compared with those associated with the Reynolds, Turbulent Kinetic Energy (TKE), and TKE-w' methods. The results show that the TKE, Reynolds, and log-law methods produced similar bed shear stress estimates, while the TKE- $\mathrm{w}^{\prime}$ method produced larger estimates than the other methods. The TKE- $\mathrm{w}^{\prime}$ method was found to be more suitable for bed shear stress estimation than the TKE method, but the value of its constant $C_{2}$ needed to be re-estimated. In a complex, strong, three-dimensional flow field, the height of the measurement point (relative or absolute) should be re-estimated when a single point measurement is used to estimate the bed shear stress. The results of this study provide guidance for experimental measurement of bed shear stress in a complex flow field.
\end{abstract}

Keywords: $60^{\circ}$ bend; bed shear stress; turbulent kinetic energy; Reynolds shear stress; log-law

\section{Introduction}

Bed shear stress is a basic variable in the study of fluvial processes [1]. It is very difficult to estimate bed shear stress via experimental methods, particularly for complex, three-dimensional flow fields. The resistance balance method is the basic method used for calculating bed shear stress, but it is not suitable for local shear stress estimations. In addition, for a flume with limited length, measurements of the water surface profile often have large errors, which can greatly influence the calculated value of bed shear stress. The local mean bed shear stress can also be measured by a shear plate sensor in small-scale and large-scale laboratory flumes [2].

With the development of advanced velocity measurement devices such as the Acoustic Doppler Velocimeter (ADV), many researchers have calculated bed shear stress by measuring flow velocity directly. The local bed shear stress can be calculated by the Turbulent Kinetic Energy (TKE) method [3] as follows:

$$
\tau_{0}=\frac{1}{2} C_{1} \rho\left(\overline{u^{\prime 2}}+\overline{v^{\prime 2}}+\overline{w^{\prime 2}}\right)
$$

where $u^{\prime}, v^{\prime}$, and $w^{\prime}$ are the velocity fluctuations of the streamwise, transverse, and vertical components $\left(u^{\prime}=u-\bar{u}, \mathrm{v}^{\prime}=v-\bar{v}\right.$, and $\left.\mathrm{w}^{\prime}=w-\bar{w}\right)$, respectively, and $C_{1}$ is a proportionality constant $(0.19)$.

Kim et al. [3] proposed a modified Turbulent Kinetic Energy method (TKE- $w^{\prime}$ method) that uses only vertical velocity fluctuations, as ADV noise errors associated with vertical velocity variances 
are smaller than the noise errors associated with horizontal velocity fluctuations (Voulgaris and Trowbridge, [4]).

$$
\tau_{0}=C_{2} \rho\left(\overline{w^{\prime 2}}\right)
$$

where $C_{2}$ is a proportionality constant (0.9).

The bed shear stress values are generally considered close to the Reynolds stress values near the bed. The local bed shear stress can also be calculated by the Reynolds stress (Reynolds method) [3,5]:

$$
\tau_{0}=-\rho\left(\overline{\mathbf{u}^{\prime} w^{\prime}}\right)
$$

Where possible, the bed shear stress is usually extrapolated from the Reynolds stress at the bed [6,7]. Reynolds stress values measured directly near the bed can also be used [8].

For a flow with a bed, when the mainstream has a fully developed turbulence flow, the flow can be divided into an inner region and an outer layer, depending on the normal distance from the bed (Figure 1). The outer layer is the fully developed turbulence flow. In the inner region, the flow is different from that in the outer layer because of the influence of the bed. The inner region can be divided into three sub-layers. Theoretically, the bed shear stress can be determined from measuring the velocity of the viscous sub-layer, according to the linear distribution of the velocity. However, because of the very thin viscous sub-layer, the normal distance from the bed is usually on the order of $0.1 \mathrm{~mm}$, which is difficult to measure. PIV has been used to measure the velocity of viscous sub-layers, but the velocity of the flow should be limited to a low-velocity range. In addition, PIV has strict requirements for the measuring environment. Light conditions, sampling frequency, sampling size, etc., would affect the measurement results, and even the temperature of the water must be controlled within a stable range. Otherwise, changes to water temperature may also cause displacement of the laser disc and camera focus plane [9]. The viscous shear stress and turbulent shear stress in the buffer region are equivalent, the flow structure is complicated, and the velocity distribution cannot be expressed by a formula or law. In the turbulent log-law region, turbulent shear stress dominates, and the velocity distribution in this region conforms to logarithmic law distribution. Because the viscous sub-layer and buffer region account for a small proportion of the total flow depth, the velocity distribution of the full flow depth in a simple open channel generally conforms to a logarithmic law distribution; thus, bed shear stress can be obtained by fitting the logarithmic law to the flow velocity (the log-law method) [1,10]:

$$
\frac{u}{u_{*}}=\frac{1}{\kappa} \ln \left(\frac{z_{\mathrm{a}}}{z_{0}}\right)
$$

where $u$ is the velocity, $u *$ is the friction velocity $\left(=\sqrt{\frac{\tau_{0}}{\rho}}\right), z_{\mathrm{a}}$ is the height above the bed, $\kappa$ is von Karman's constant (0.4), and $z_{0}$ is the statistical roughness length.

Application of this method only requires measuring the time-averaged velocity to obtain the friction velocity $u *$, using a series of measured $\left(u, z_{\mathrm{a}}\right)$ values to carry out logarithmic fitting, which greatly reduces the influence of larger individual error velocity points. Although this method is widely used, there remains a problem with the accuracy of data fitting [11]. In a complex flow field, the velocity distribution of the total depth typically does not satisfy the logarithmic law distribution. The number of measured velocity points and the height error of the measuring points greatly influence the calculation results.

There have been many studies on bed shear stress in the case of uniform flow [12,13], but few studies have estimated bed shear stress in cases of complex flow fields, especially complex flow fields in bends [14]. However, natural rivers, in practice, often have bends, and the flow pattern is complex [15]. In a complex flow field, although it is difficult to satisfy the logarithmic distribution of the total flow depth, the bed shear stress can also be calculated using the velocity distribution of the turbulent log-law region near the bed. In this study, based on the flow field measurements of a $60^{\circ}$ bend movable bed experiment, the feasibility and reliability of the log-law method in the complex flow 
field of the bend were analyzed, and the results were compared with those predicted by the Reynolds, TKE, and TKE-w' methods.

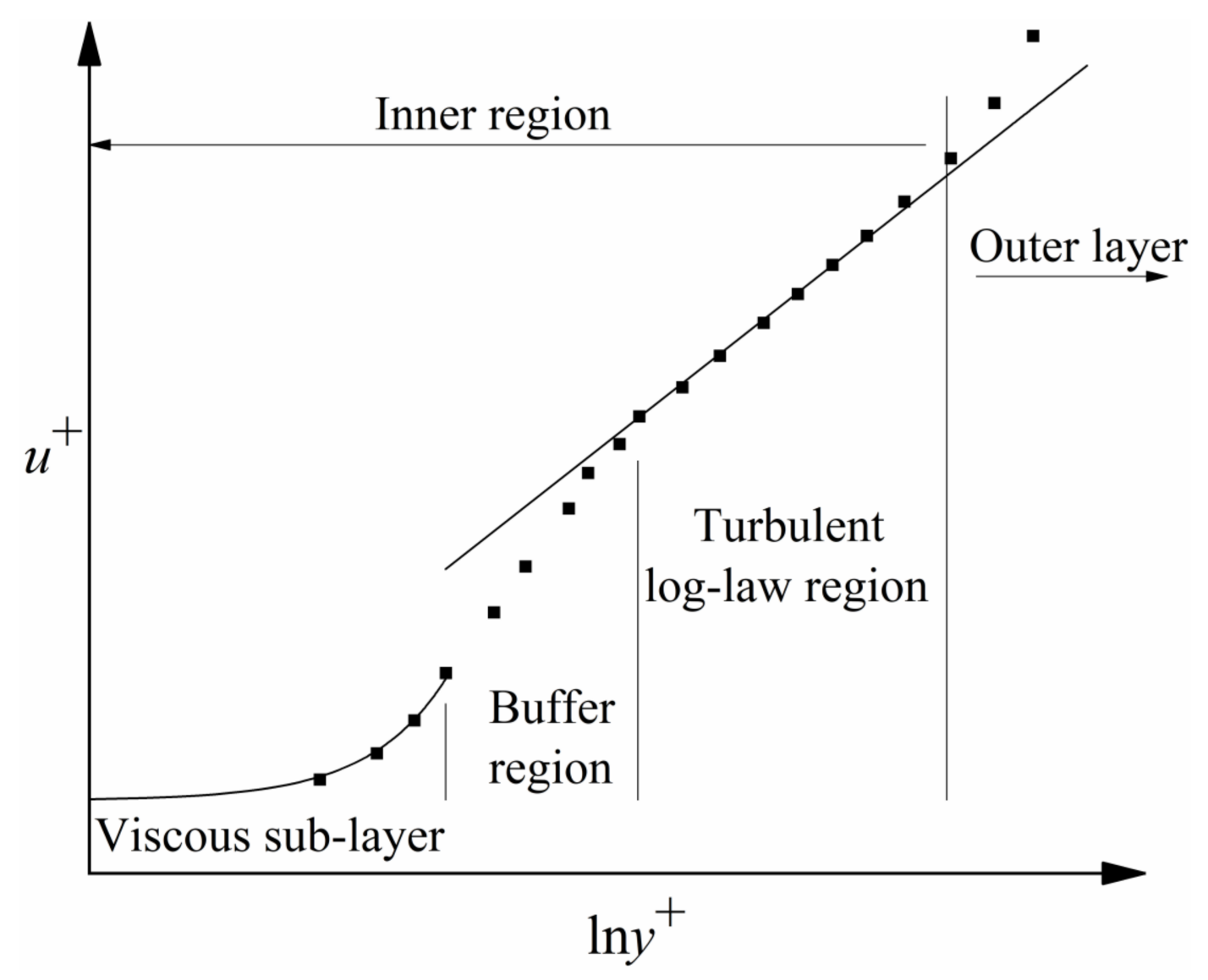

Figure 1. Velocity distribution near the bed $\left(u^{+}=u / u_{*}, y^{+}=\frac{u_{*} y}{v}\right)$.

\section{Experimental Setup}

The experiment was carried out in a $0.6 \mathrm{~m}$ wide, $14.4 \mathrm{~m}$ long recirculating flume with a longitudinal slope (i) of 0.001 , located in the Sichuan University's State Key Laboratory of Hydraulics and Mountain River Engineering. The main channel consisted of a $7 \mathrm{~m}$ long upstream, a $60^{\circ}$ channel bend with a centerline radius bend $\left(R_{c}\right)$ of $4.2 \mathrm{~m}$, and a $3 \mathrm{~m}$ long downstream straight reach. The groyne, with a thickness of $0.01 \mathrm{~m}$, was positioned at the $30^{\circ}$ center corner of the outer bank side of the bend. The length of the groyne wing and web was $0.1 \mathrm{~m}$ (Figure 2a). To stabilize the flow, an energy dissipation grid was placed at the inlet of the flume. The measured cross-sections $S 0-S 33$ corresponded to the central angles of $0-33^{\circ}$, respectively, of the bend. Figure $2 \mathrm{c}$ shows a vertical view of the section measurements in section $S 29.5$, and Figure $2 \mathrm{~d}$ is a three-dimensional illustration of the groyne with a submergence ratio $(H-h) / h=1$.

Table 1 lists the experimental flow conditions and values of some experimental parameters, such as the median sediment particle size $d_{50}$. Clear water scouring was used in the experiment. The ratio of the velocity of the approaching flow $U_{0}$ to the critical velocity of the sediment $v_{c}$ was $92.5 \%$. Because the sediment was sand, the critical velocity of the sediment was calculated by the Zhang Ruijin formula as defined in Equation (5) [16]:

$$
v_{\mathcal{C}}=\left(\frac{H}{d_{50}}\right)^{0.14} \sqrt{17.6 \frac{\gamma_{s}-\gamma}{\gamma} d_{50}+0.000000605 \frac{10+H}{d_{50}^{0.72}}}
$$


where $v_{c}$ is the critical velocity of the sediment $(\mathrm{m} / \mathrm{s}), d_{50}$ is the median sediment particle size $(\mathrm{m})$, $H$ is the approaching flow depth $(\mathrm{m})$, and $\gamma_{s}$ and $\gamma$ are the unit weights of the sand and water, respectively $\left(\mathrm{kN} / \mathrm{m}^{3}\right)$.

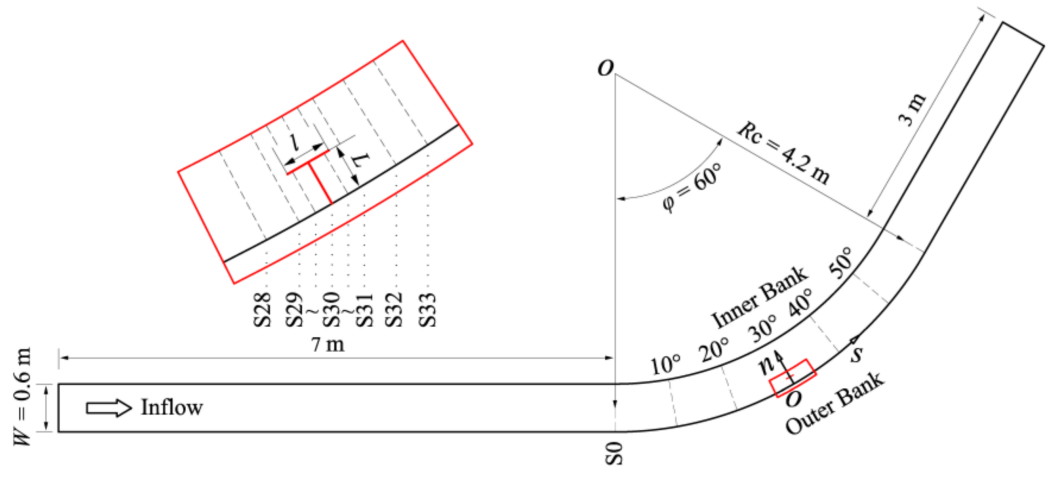

(a)

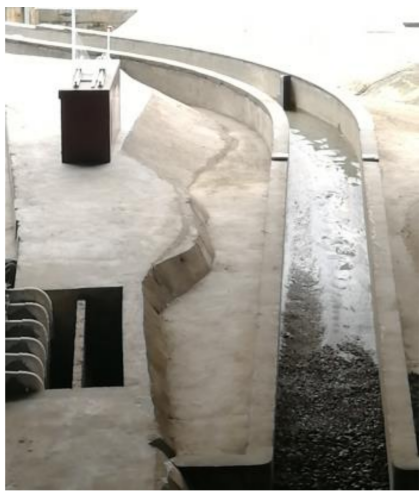

(b)

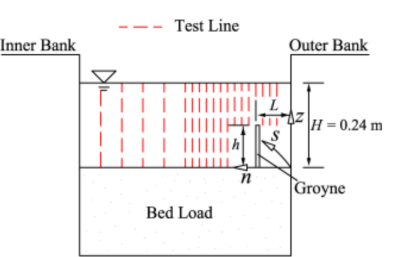

(c)

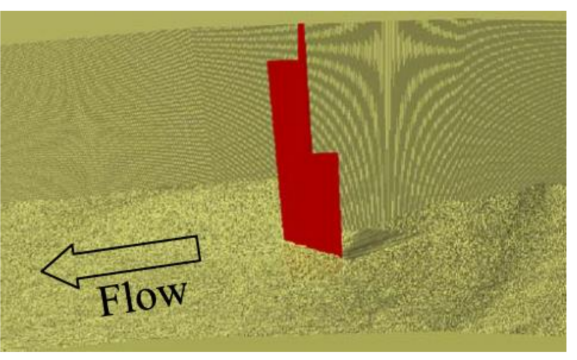

(d)

Figure 2. Details of experiment setup: (a) plan view parameters related to the experimental flume and arrangement of the cross-sections; (b) experimental flume; (c) test lines (S29.5); (d) groyne.

Table 1. Experimental parameter values.

\begin{tabular}{cccccccccc}
\hline$Q\left(\mathbf{m}^{\mathbf{3}} / \mathbf{s}\right)$ & $F \mathbf{r}$ & $\boldsymbol{H}(\mathrm{m})$ & $R \mathrm{c} / W$ & $d_{\mathbf{5 0}}(\mathrm{m})$ & $\gamma_{s}\left(\mathbf{k N} / \mathbf{m}^{3}\right)$ & $\gamma\left(\mathbf{k N} / \mathbf{m}^{3}\right)$ & $U_{\mathbf{0}}(\mathrm{m} / \mathbf{s})$ & $v_{c}(\mathrm{~m} / \mathbf{s})$ & $U_{\mathbf{0}} / v_{c}$ \\
\hline 0.0428 & 0.19 & 0.24 & 7 & 0.000642 & 25.8 & 9.8 & 0.297 & 0.321 & $92.5 \%$ \\
\hline
\end{tabular}

Because $U_{0} / v_{c}<1$, the bed sediment is basically stable in the upstream section, while in the bend of the groyne, the velocity increases because of the reduction in the flow cross-section, thus achieving clean water scouring. The experiment was designed to ensure that the sediment in the test sections reached an equilibrium state during the test period of $86 \mathrm{~h}$.

The topographic measurement instrument used was a RIEGL VZ400 laser scanner with a maximum scanning distance of $600 \mathrm{~m}$ and a single-point scanning accuracy of $2 \mathrm{~mm}$ at $100 \mathrm{~m}$. The instrument had good applicability in measuring moving bed experiments [17]. A Vectrino Profiler manufactured by Nortek Corporation was used for velocity measurements. This device consists of a down-looking measurement probe with a non-measurable region of $4 \mathrm{~cm}$, a signal regulator, and a signal processor. The device can measure velocity within a range of $3 \mathrm{~cm}$ at one time, with a minimum layer thickness of $1 \mathrm{~mm}$ (that is to say, the velocity of 30 measuring points can be measured at the same time), an accuracy of $\pm 1 \mathrm{~mm} / \mathrm{s}$, and a sampling frequency of $100 \mathrm{~Hz}$. In the experiment, 3000 velocity samples were collected at one time. In other studies, some researchers have removed measurements with correlation coefficients below 70\% and signal-to-noise ratios (SNRs) below $15 \mathrm{~dB}$ when processing data [13,14]. Considering that the validity and accuracy of the bed shear stress calculation in this experiment 
depended on the accuracy of the velocity measurement, the correlation coefficients and SNRs of less than $90 \%$ and $30 \mathrm{~dB}$, respectively, were eliminated, and suspected spikes were removed using the phase-space threshold method [18]. The distance between the velocity of each layer and the bed surface was automatically measured by the instrument, which greatly reduced the error compared to that which would have resulted from manual measurement. This provided a more reliable and effective method for analyzing the velocity distribution near the bed than single-point ADV.

\section{Methods}

In the flow field of the bend considered in this experiment, there was transverse velocity. The bed shear stress obtained using the Reynolds method consisted of two parts: streamwise shear stress $\left(-\rho\left(\overline{u^{\prime} w^{\prime}}\right)\right)$ and transverse shear stress $\left(-\rho\left(\overline{v^{\prime} w^{\prime}}\right)\right)$. Similarly, the bed shear stress obtained by the log-law method consisted of the streamwise shear stress calculated from the time-averaged velocity in the streamwise direction $(s)$ and the transverse shear stress calculated from the time-averaged velocity in the transverse direction $(n)$. Because the flow field in this experiment belonged to a strong three-dimensional complex flow field, it was difficult to obtain the extrapolated values for the bed by the Reynolds, TKE, and TKE- $\mathrm{w}^{\prime}$ methods. Therefore, the bed shear stress was calculated by measuring the corresponding maximum value near the bed.

Figure 3a,b shows the shear stress distributions along the test line $(n / L=1.4$, S29) according to the TKE method (Equation (1)) and TKE- $w^{\prime}$ method (Equation (2)), respectively. The bed shear stress was the peak-value at about $z_{\mathrm{a}}=0.05 \mathrm{~m}$ above the bed.

Figure $3 c$,d gives the Reynolds shear stress distributions in the streamwise $(s)$ and transverse (n) directions, respectively, calculated by the Reynolds method (Equation (3)) along the test line $(n / L=1.4, S 29)$.

The two directions of shear stress increased rapidly from the bottom of the bed and reached the peak-values at $z_{\mathrm{a}}=0.015 \mathrm{~m}$ and $z_{\mathrm{a}}=0.010 \mathrm{~m}$, respectively. As shown in Figure 3a, with the increasing distance from the bed $\left(0<z_{\mathrm{a}}<0.05\right)$, the turbulence of the flow increased rapidly. When the distance from the bed was bigger than $0.05 \mathrm{~m}$, the turbulence of the flow gradually decreased. Figure 3e,f shows the velocity distribution along test lines $(n / L=1.4, S 29$ and $n / L=4.8, S 42$, respectively). In general, streamwise velocity $(u)$ was more in accordance with a logarithmic distribution than the transverse velocity $(v)$. The transverse velocity $(v)$ was only consistent with a logarithmic distribution in the vicinity of the bed. The values obtained for the coefficient of determination $R^{2}$ of the logarithmic fitting formula for various cases were greater than 0.8. Using the fitting formula and Equation (4), the bed shear stress at the corresponding measuring point can be calculated.

The positive Reynolds stress $\left(-\rho\left(\overline{u^{\prime} w^{\prime}}\right)\right.$ ) of the liquid particle corresponded to the positive time-averaged velocity gradient $\left(\frac{d \bar{u}}{d z}\right)$, and the negative Reynolds stress corresponded to the negative time-averaged velocity gradient. According to Prandtl's mixing length theory, the Reynolds stress value was related to the time-averaged velocity gradient as follows:

$$
-\rho\left(\overline{u^{\prime} w^{\prime}}\right)=\rho l^{2}\left(\frac{d \bar{u}}{d z}\right)^{2}
$$

where $l$ is the mixing length, $l=\kappa y ; \kappa$ is a dimensionless constant. Figure $3 \mathrm{~d}$,e shows that during $0<z_{\mathrm{a}}<0.025$, the positive velocity gradient corresponded to the positive Reynolds stress, and during $0.025<z_{\mathrm{a}}<0.120$, the negative velocity gradient corresponded to the negative Reynolds stress. During $0.12<z_{\mathrm{a}}<0.17$, the velocity gradient was small, and its corresponding Reynolds stress value was basically zero. 


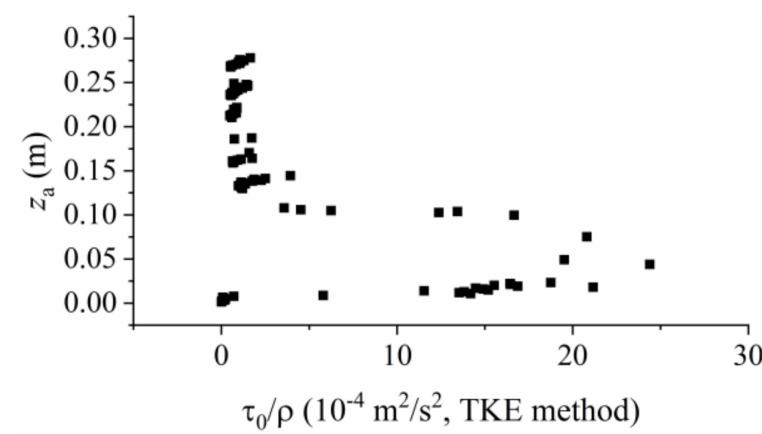

(a)

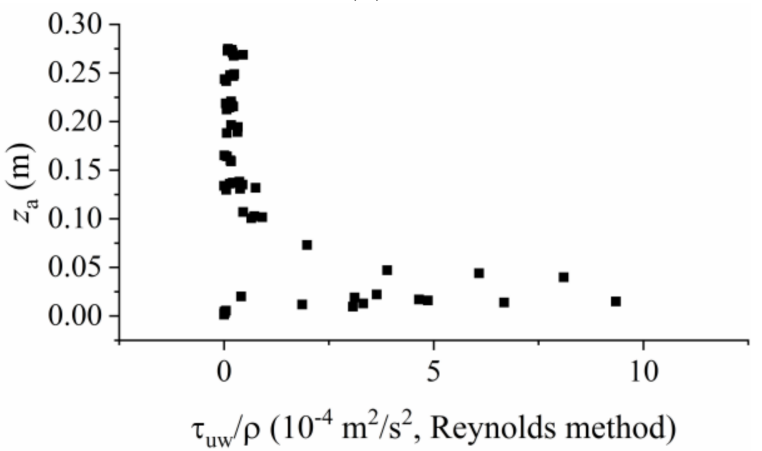

(c)

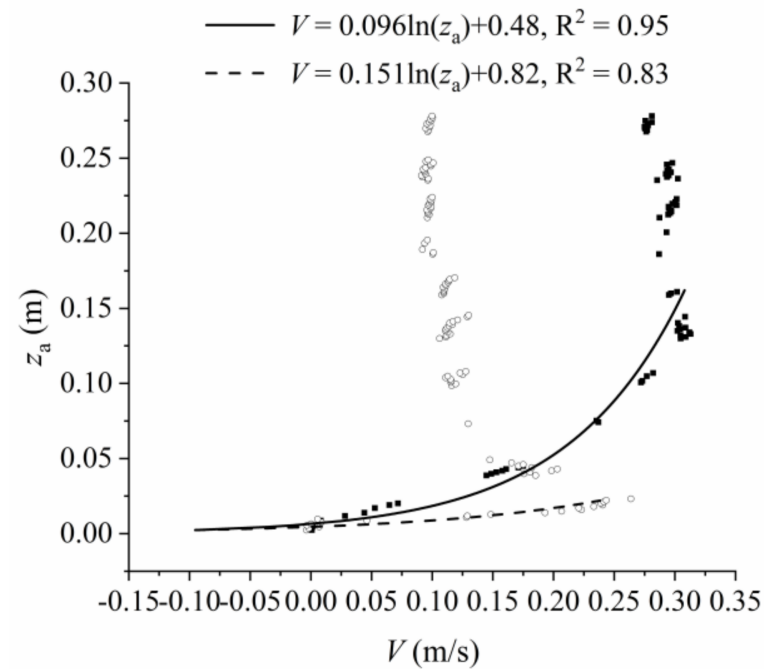

(e)

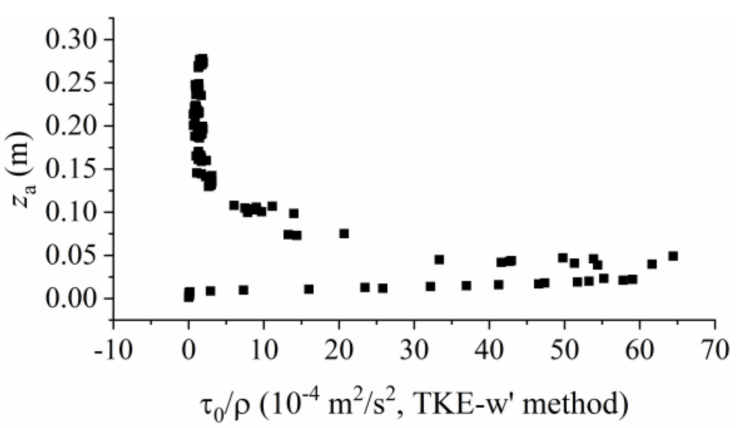

(b)

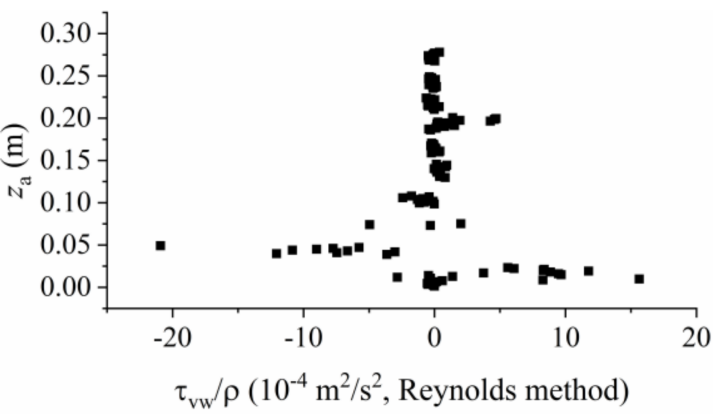

(d)

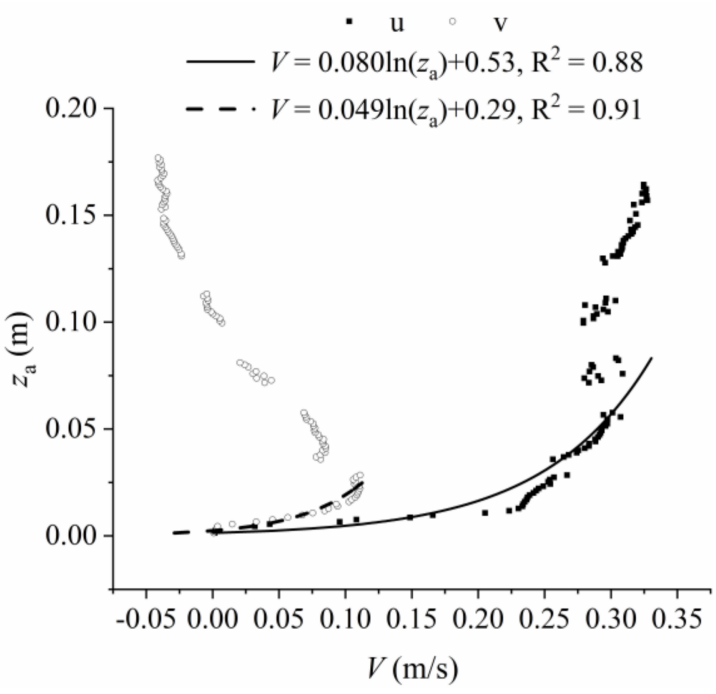

(f)

Figure 3. Bed shear stress estimates: (a) TKE method $(n / L=1.4, S 29)$; (b) TKE-w' method $(n / L=1.4$, S29); (c) Reynolds method ( $n / L=1.4$, S29); (d) Reynolds method $(n / L=1.4, S 29)$; (e) log-law method $(n / L=1.4, S 29)$; (f) log-law method $(n / L=4.8, S 31)$.

\section{Results and Discussion}

\subsection{Comparison of Methods for Bed Shear Stress Estimates in Selected Sections}

Figure 4 shows a comparison of the four methods for bed shear stress estimates in selected sections. The values estimated according to the four methods were basically the same in trend and value. The entrance section $S 0$ of the bend was not affected by the groyne and could be used for analysis of the bed shear stress in a simple flow field. The trends of the four types of bed shear stress estimates along section $S 0$ were basically the same, reaching a maximum at $n / L=2.4$. The measurement values according to each method changed slightly along the section, as section $S 0$ was at the entrance 
of the bend, and the influence of the bend on the flow field was still weak at that point. The bed shear stress in the middle of the flume was slightly greater than that on the banks because of the retarding effect of the side wall of the flume on the flow. In section $S 0$, the results obtained with the TKE method and Reynolds method were the most similar, followed by those obtained with the log-law method, while the values obtained with the TKE-w' method were the largest of those obtained with the four methods.

In regions S29-S33, there was a strong three-dimensional flow field because of the combined effect of the bend and the groyne. On the upstream side of groyne (S29-S29.5), the bed shear stress on the outer side $(1<n / L<3)$ was significantly larger than that on the inner side $(3<n / L<6)$. The values for the flow fields in each section, obtained using the TKE-w' method, were typically larger than those obtained with the log-law, TKE, and Reynolds methods, but there was little difference between the values obtained with the other three methods for the inner side $(3<n / L<6)$, where the bed shear stress level was relatively low. The distribution of the bed shear stress in section S29 was similar to that in section S29.5. The bed shear stress in section S29.5 was lower than that in section S29 in the range of $0<n / L<1$ because the region $(0<n / L<1, S 29.5)$ was within the wing of the groyne, and the flow turbulence and velocity were suppressed. Sections S30.5-S32 were on the downstream side of the groyne. The bed shear stress in the middle of the flume $(1.2<n / L<4)$ decreased gradually in the flow direction, and the bed shear stress in the region of the groyne wing $(0<n / L<1)$ increased gradually. This is because, with increasing distance from the groyne, the influence of the groyne on the flow turbulence and velocity in the middle of the flume decreased, and the bed shear stress was lower. However, the restraint effect of the groyne on the flow turbulence and velocity inside the groyne wing gradually decreased, and the bed shear stress increased accordingly. In section S33, aside from the values obtained with the TKE- $\mathrm{w}^{\prime}$ method in the range of $0<n / L<1$, the bed shear stress for whole sections tended to be stable, and the bed shear stress on the inner side of the groyne wing $(0<n / L<1)$ decreased, indicating that the distribution of the downstream bed shear stress became progressively less influenced by the groyne.

Despite errors in the measurement of the Reynolds stress, the Reynolds method is considered to be relatively reliable $[6,14,19]$. In Figure 5, the TKE method, TKE- $w^{\prime}$, and log-law methods were fitted linearly with a zero intercept, with slopes of $0.836\left(R^{2}=0.070\right), 2.035\left(R^{2}=0.673\right)$, and $0.841\left(R^{2}=0.290\right)$, respectively. The slope of the solid line is 1 . The slope of the log-law method was closest to 1 , as shown in Figure 5, indicating that it was closer to the Reynolds method values at both low and high stress levels (Figure 5). The slope of the TKE- $\mathrm{w}^{\prime}$ method was much greater than 1, as shown in Figure 5, which indicated that the stress values were significantly greater than the Reynolds method values for both low and high stress levels. The slope of the TKE method was close to that of the log-law method, but its $R^{2}$ was the smallest, indicating the greatest dispersion, which was higher than that of the Reynolds method at low stress levels and lower than that of the Reynolds method at high stress levels (Figure 5).

Figure 6a shows topographic illustrations of bed scouring around the groyne (positive values represent silting; negative values represent scouring). The scouring depth was the highest at the upstream head of the groyne, while sediment deposits occurred at the inner bank. Figure 6b shows the velocity distribution near the groyne. The velocity vectors indicate the depth-averaged velocity vectors (UV components) and depth-averaged vertical velocity-filled contours (W component, positive values represent the upward velocity). Figure $6 c-f$ shows the bed shear stress contours (using the Kriging method) for the TKE, TKE-w', Reynolds, and log-law methods, respectively. There were two high bed shear stress zones identified by the four methods. The first one was located on the upstream side near the groyne, where both the horizontal and vertical velocities were large; the second one was located on the downstream side at a distance from the groyne, where the horizontal velocity was lower than in the surrounding area, but the vertical velocity was higher than in the surrounding area, so the vertical velocity in this area contributed greatly to the formation of high bed shear stress. The bed shear stress in the second area was smaller than that in the first area, mainly because of the 
lower horizontal velocity (Figure 6b). Chrisohoides et al. (2003) and Biron et al. (2004) assumed that there was a strong correlation between the scouring area and high bed shear stress [14,20]. The four types of bed shear stress distribution contours identified in this study had certain similarities with the topographic contours. High bed shear stress corresponded to scouring area, but the bed shear stress in the deepest scouring area enclosed by the side wall and groyne wing on the upstream side of the groyne was relatively small and was mainly located in the back-flow zone with low velocity (Figure 6b).

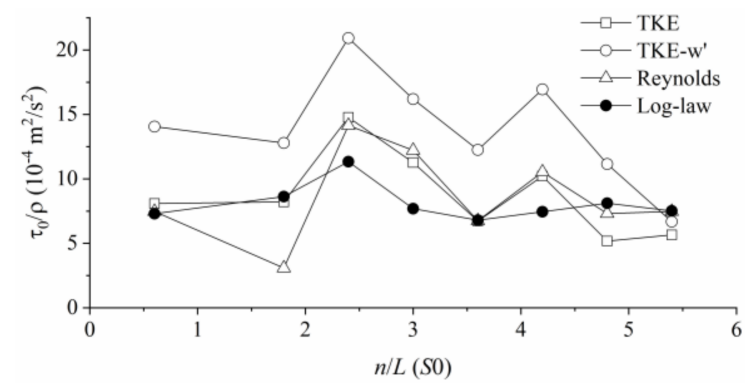

(a)

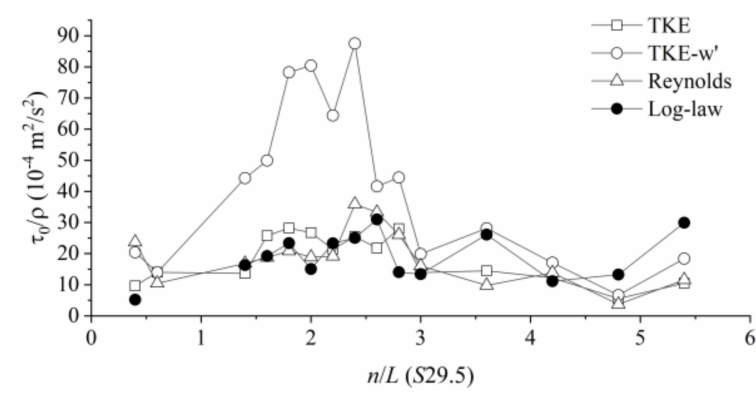

(c)

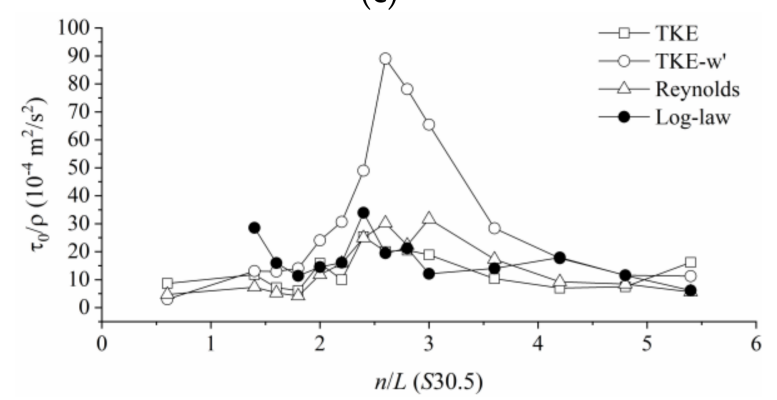

(e)

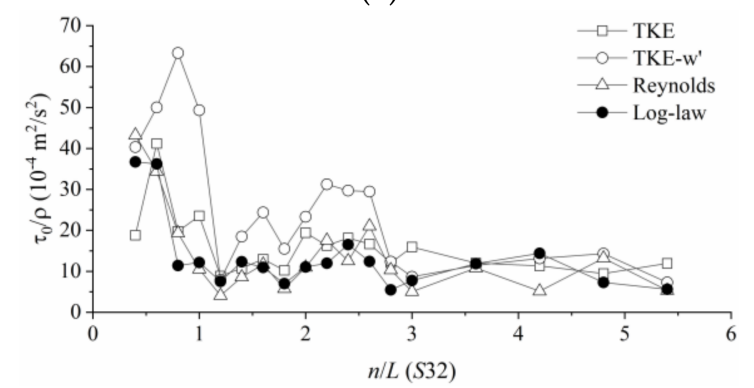

(g)

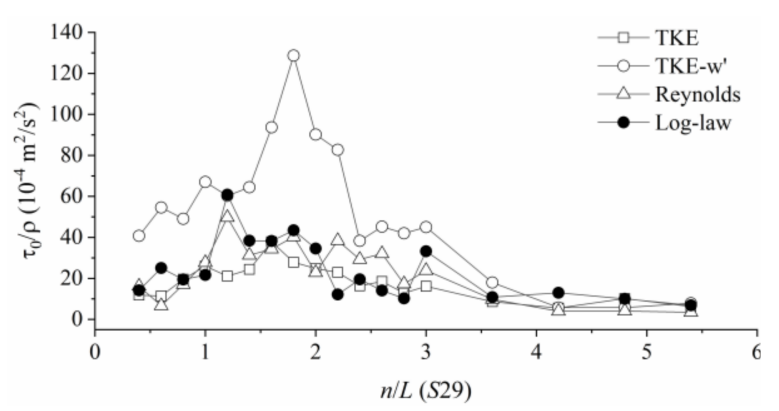

(b)

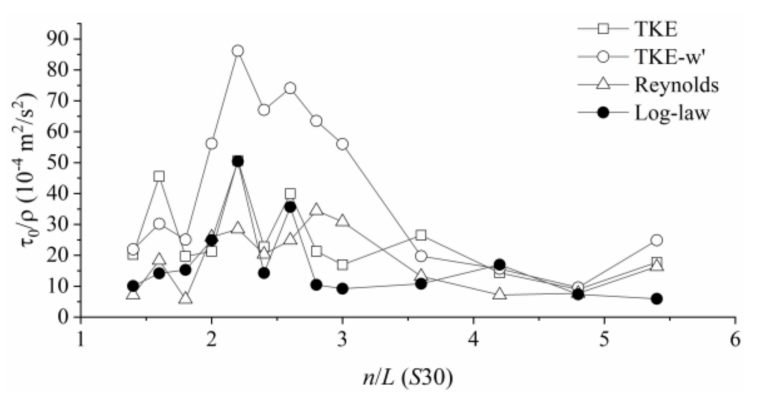

(d)

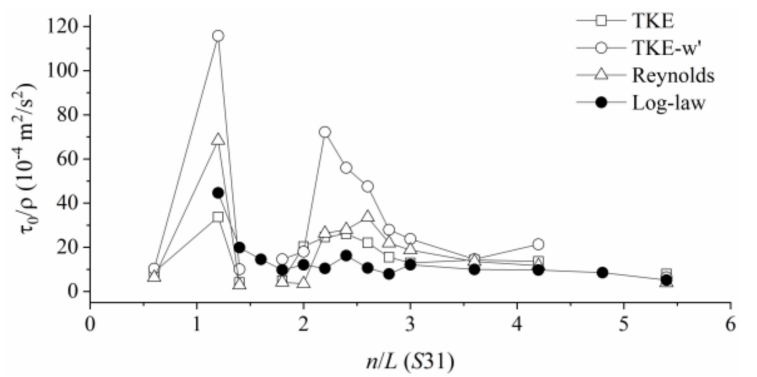

(f)

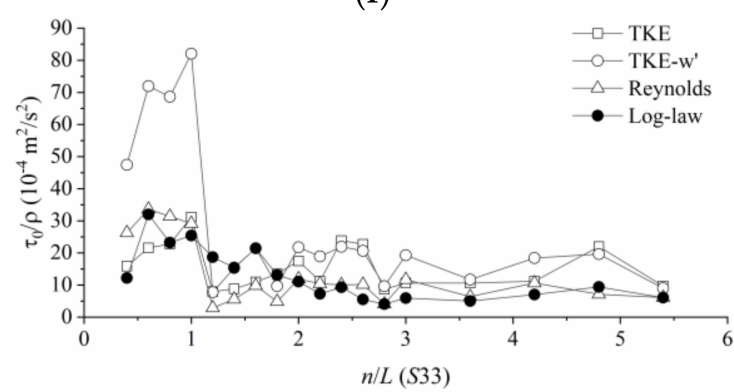

(h)

Figure 4. Comparison of results from four methods for bed shear stress estimates in selected sections: (a) S0; (b) S29; (c) S29.5; (d) S30; (e) S30.5; (f) S31; (g) S32; (h) S33. 


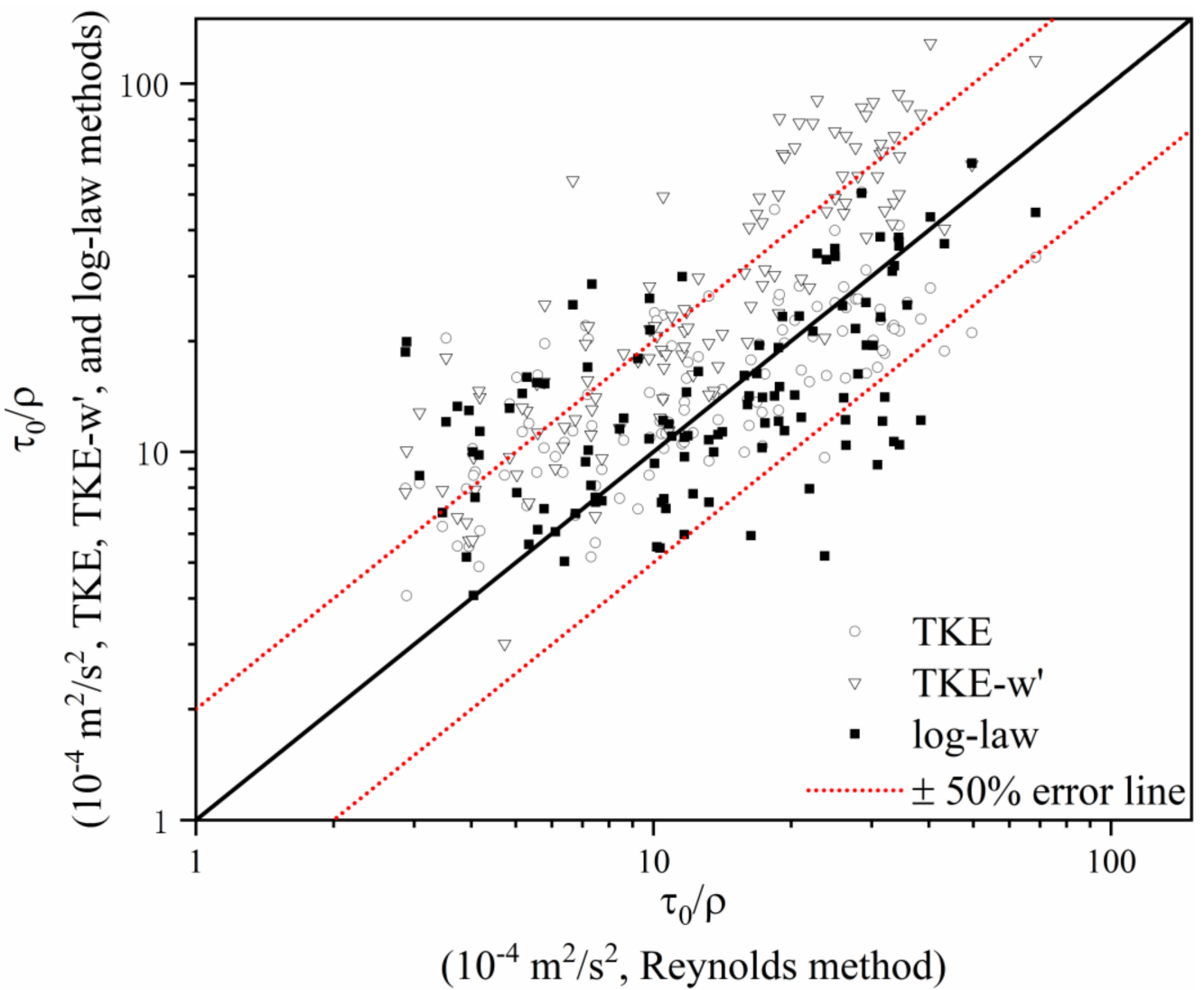

Figure 5. Comparison of Reynolds method with the TKE, TKE-w' ${ }^{\prime}$, and log-law methods.

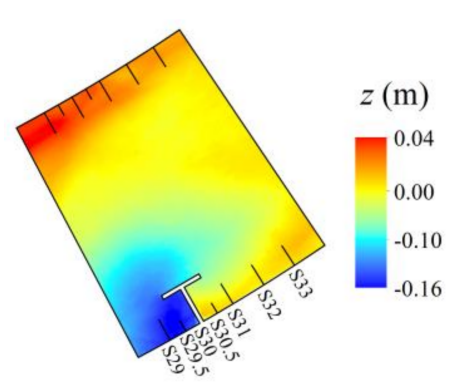

(a)

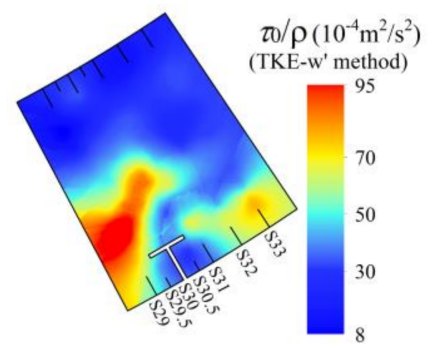

(d)

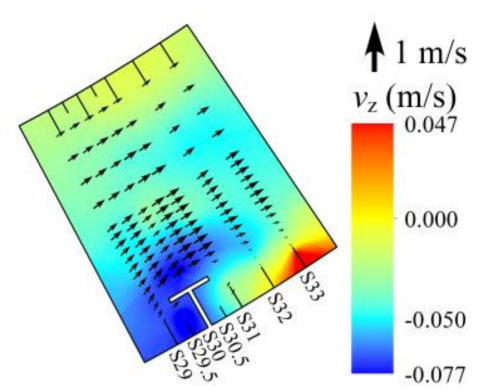

(b)

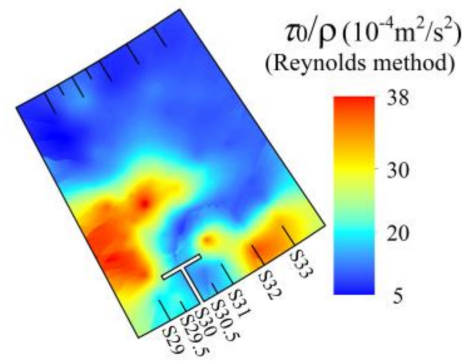

(e)

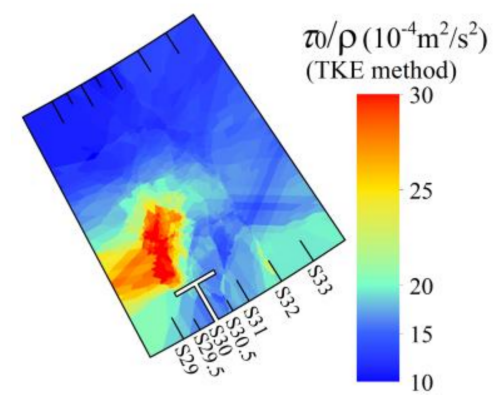

(c)

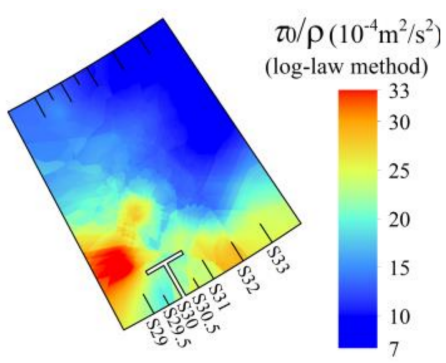

(f)

Figure 6. (a) Bed topography around the groyne; (b) depth-averaged velocity vectors (UV components, " $1 \mathrm{~m} / \mathrm{s}$ " corresponds to the size of the arrow on the left) and depth-averaged vertical velocity filled contours (W component, positive values represent upward velocity); (c) bed shear stress (TKE method); (d) bed shear stress (TKE-w' method); (e) bed shear stress (Reynolds method); (f) bed shear stress (log-law method). 


\subsection{Re-Estimation of Parameters of TKE and TKE-w' Methods}

The values of the constants $\left(C_{1}\right.$ and $\left.C_{2}\right)$ of the TKE and TKE- $\mathrm{w}^{\prime}$ methods may vary dramatically near the bed, so they can be re-estimated based on measurements obtained in the laboratory or in natural rivers [14].

According to the calculation results presented in the previous section (Figure 5), the values of the constants $C_{1}$ and $C_{2}$ were adjusted to 0.23 and 0.44 , and the bed shear stress values according to the $\mathrm{TKE}$ and TKE- $\mathrm{w}^{\prime}$ methods were recalculated. Figure 7 shows linear regressions with zero intercepts using the TKE and TKE- $\mathrm{w}^{\prime}$ methods, with slopes of $1\left(R^{2}=0.070\right)$ and $1\left(R^{2}=0.673\right)$, respectively. The slope of the solid line is 1 . After adjusting the parameter values, the slopes of the regressions for the TKE method and the TKE- $w^{\prime}$ method were 1 , but the $R^{2}$ for the former method was much smaller than that for the latter, indicating that there was much more scatter in the TKE results, probably due to the higher error associated with the horizontal components of velocity [14]. Based on the experimental results obtained in this study, the TKE- $w^{\prime}$ method was judged to be more suitable for use in bed shear stress estimations than the TKE method, but the value of its constant $C_{2}$ needed to be re-estimated. In this study, the re-estimated values of constants $C_{1}$ and $C_{2}$ varied by $21.1 \%$ and $51.1 \%$, respectively, compared with the original values. Compared with the TKE-w' method, the variation in the value of the TKE method's constant $C_{1}$ was smaller, and the slope of the regression for the Reynolds method was closer to 1 (Figure 5) with no change in the constant. Therefore, when the constant values were not re-estimated or could not be estimated, the TKE method may yield more reasonable bed shear stress estimates than the TKE- $\mathrm{w}^{\prime}$ method. More experiments are needed to verify whether the TKE method performs better under other experimental conditions.

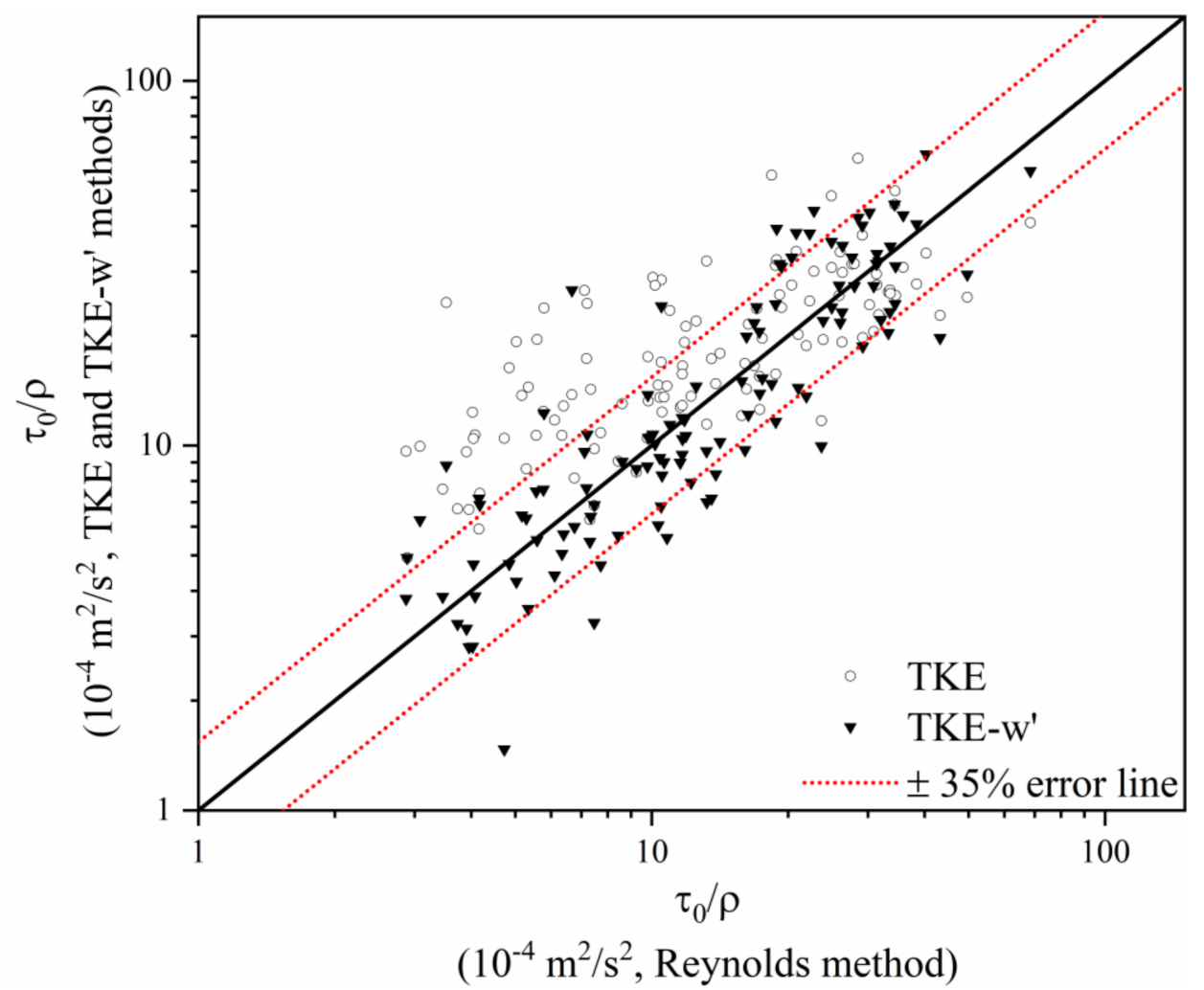

Figure 7. Comparison of Reynolds method with the TKE and TKE- $w^{\prime}$ methods after re-estimation of parameters. 


\subsection{Transverse Bed Shear Stress}

The overall magnitude of the bed shear stress is often of greater concern than the magnitudes of the directional components of the bed shear stress, especially the transverse bed shear stress. However, the transverse transport of sediment is closely related to the value of the transverse bed shear stress [21]. Figure $8 \mathrm{a}, \mathrm{b}$ shows the transverse bed shear stress estimated by the Reynolds method and the log-law method, respectively. In Figure $8 \mathrm{a}, \mathrm{b}$, the difference is small in the high shear stress region, but large in the low shear stress region. Therefore, it is difficult to apply the logarithmic law to determine the transverse shear stress under the condition of low shear stress level (usually corresponding to low transverse velocity). The maximum transverse bed shear stress occurred near the groyne wing, upstream of the groyne, because the flow was blocked by the groyne and the streamlines were deflected, resulting in high transverse velocity (Figure $6 \mathrm{~b}$ ). Because of the high transverse bed shear stress, transverse sediment transport occurred, leading to the formation of large transverse scouring zones (Figure 6a).

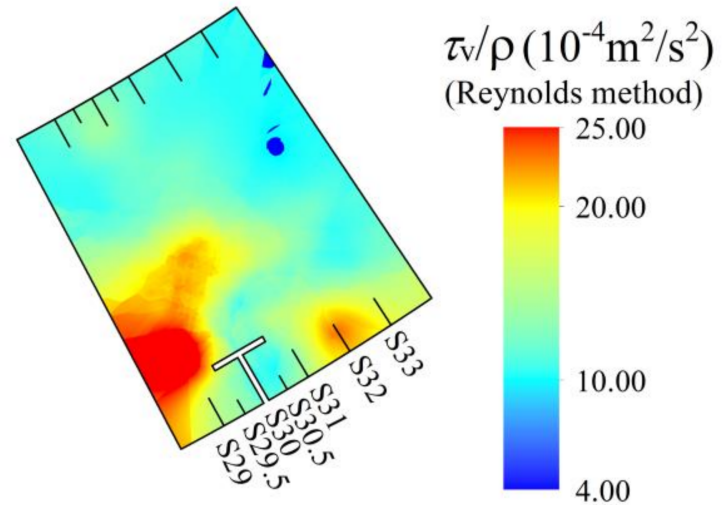

(a)
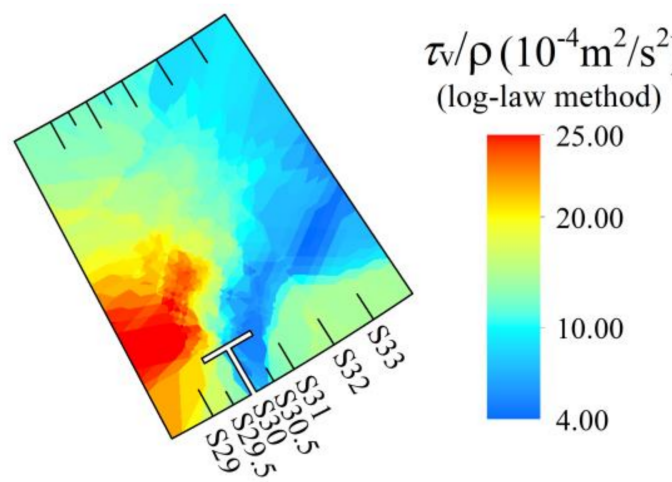

(b)

Figure 8. Transverse bed shear stress estimates: (a) Reynolds method; (b) log-law method.

Both the TKE and TKE- $\mathrm{w}^{\prime}$ methods yielded direct estimates of the bed shear stress, whereas the Reynolds method and the log-law method could be used less directly to estimate the streamwise bed shear stress and transverse bed shear stress, which correspond to the streamwise and transverse transport of the sediment, respectively, and are of great significance in the study of fluvial processes.

\subsection{Height Analysis for Single-Point Measurements}

In experiments or in observations of natural rivers, it is often very difficult to measure the velocity of full-flow-depth profiles. Single-point measurements near the bed are often used to estimate the bed shear stress. Therefore, determination of the height at which single-point measurements should be taken is an important part of estimating the bed shear stress. In fluvial studies, it is generally considered that a point close to the bed but above the roughness layer is ideal for estimating the average bed shear stress on a roughness scale (e.g., Babaeyan-Koopaei et al. [5]). Simple boundary layer flow concepts confirm that both the Reynolds shear stress and turbulent energy vary with the height above the bed, reaching a maximum value when the height of the bed is 0.1 times the depth of the water [22]. Some researchers have obtained peak-values at the same dimensionless distance (0.1) above gravel beds [6]. The applicability of this dimensionless distance 0.1 (e.g., for different bed surface roughnesses, and taking into consideration parameters of the measurement equipment, the influence of velocity, etc.) and the optimal measurement height, in terms of the absolute height above the bed or the relative height, requires further research [14]. Figure 9 shows a comparison of the peak-value heights corresponding to the TKE method, the TKE- $w^{\prime}$ method, and two directions ( $s$ and $n$ ) of the Reynolds method in section $S 0$. Because the $S 0$ section was at the entrance of the bend, where the topography changed slightly, the flow depth $H$ of each point in the section remained basically unchanged at a 
value of $H=0.24 \mathrm{~m}$. The peak-value heights for the TKE, TKE- $\mathrm{w}^{\prime}$, and Reynolds methods were not significantly different at all points in the section and varied slightly across the section. This can be expressed by a uniform height $z_{\mathrm{a}}=0.013 \mathrm{~m}\left(z_{\mathrm{a}} / \mathrm{H}=0.05\right)$.

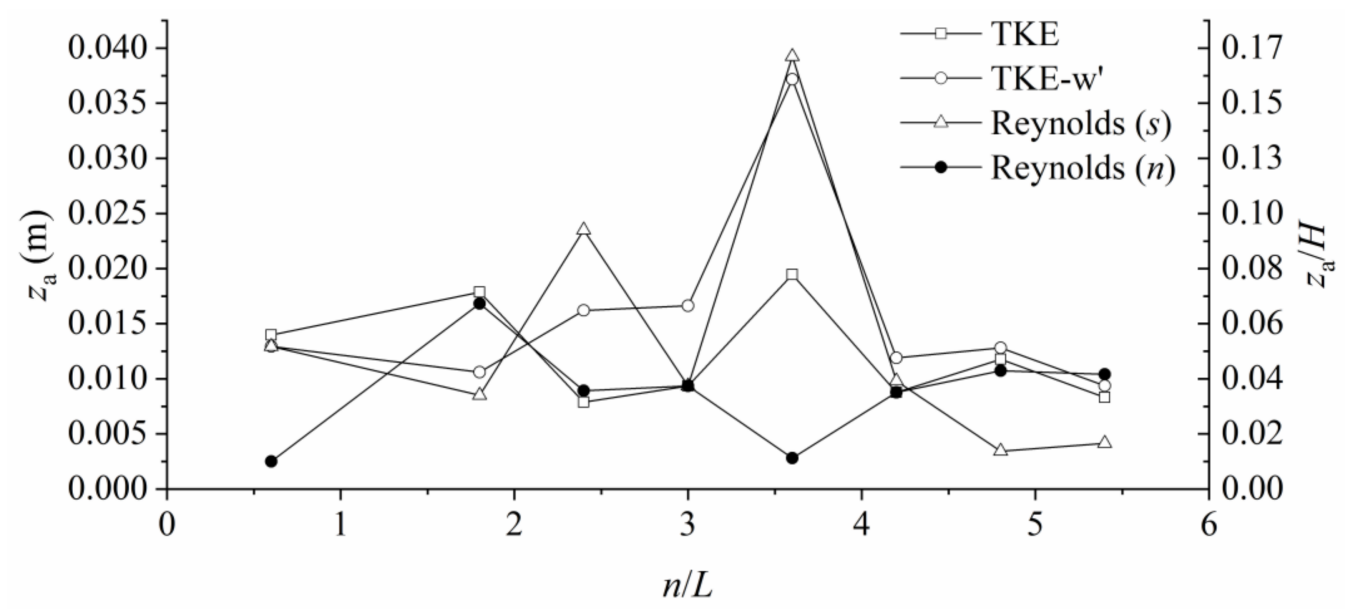

Figure 9. The peak-value heights of section $S 0$.

Figure 10 shows a comparison of the peak-value heights for the TKE method, TKE- $\mathrm{w}^{\prime}$ method, and Reynolds method ( $s$ and $n$ ) near the groyne. In this zone, because of the considerable change in the strong three-dimensional flow structure and topography, the peak-value height changes for the TKE, TKE- $w^{\prime}$, and Reynolds methods were more complicated than those for section S0, but they still had certain similarities in terms of their spatial variation. The absolute height distribution ranges (the difference between the maximum and the minimum) according to the TKE method, TKE- $\mathrm{w}^{\prime}$ method, and Reynolds method (streamwise and transverse) were $0.032,0.034,0.023$, and $0.023 \mathrm{~m}$, respectively, and the relative height distribution ranges were $0.12,0.16,0.11$, and 0.15 , respectively. The absolute height distribution range and the relative height distribution range of the TKE- $\mathrm{w}^{\prime}$ method were the largest among the three methods, and the peak-value height was the most unstable of the three methods. The absolute height distribution range $(0.023 \mathrm{~m})$ and the relative height distribution range (0.11) of the streamwise Reynolds method were the smallest of the three methods, but the range was still sufficiently large. Therefore, in a complex, strong, three-dimensional flow field, the height of the measurement point (relative or absolute) should be re-estimated when the single-point measurement is used to estimate the bed shear stress. 


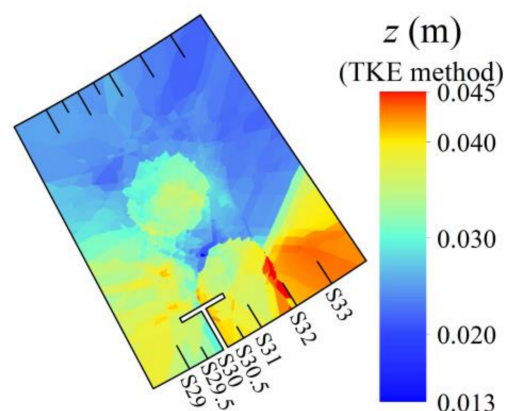

(a)

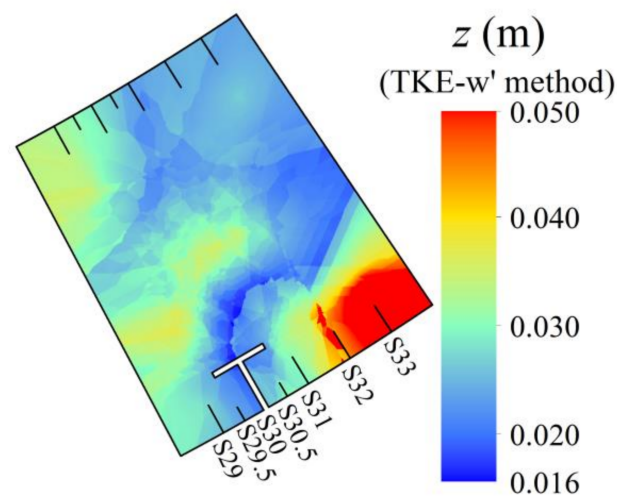

(c)

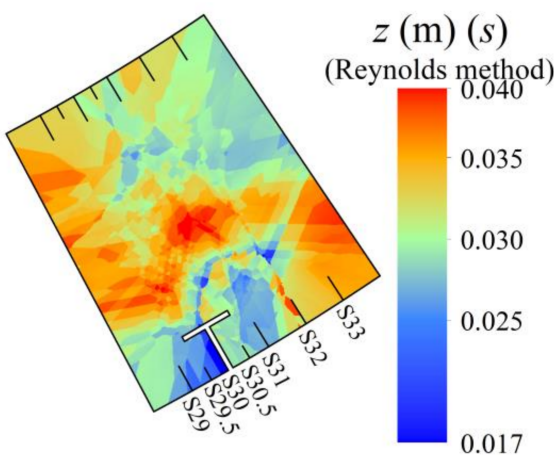

(e)

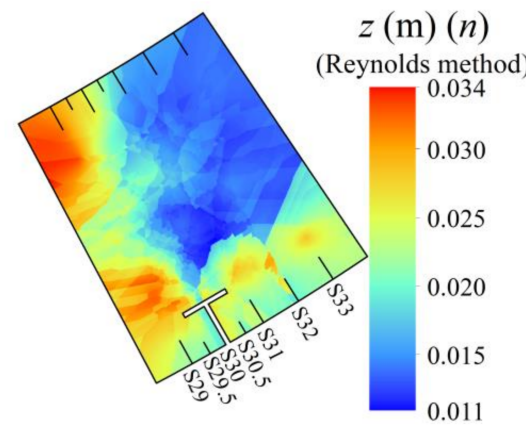

(g)

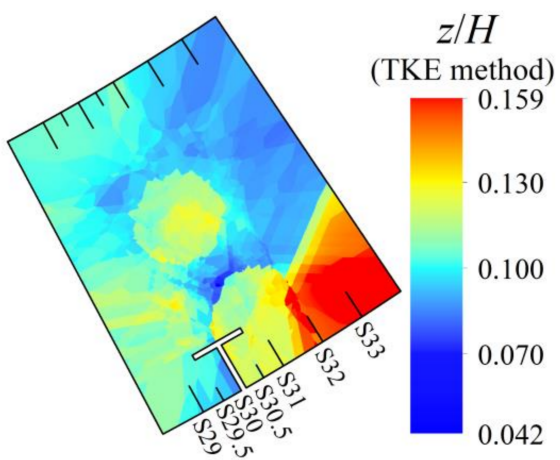

(b)

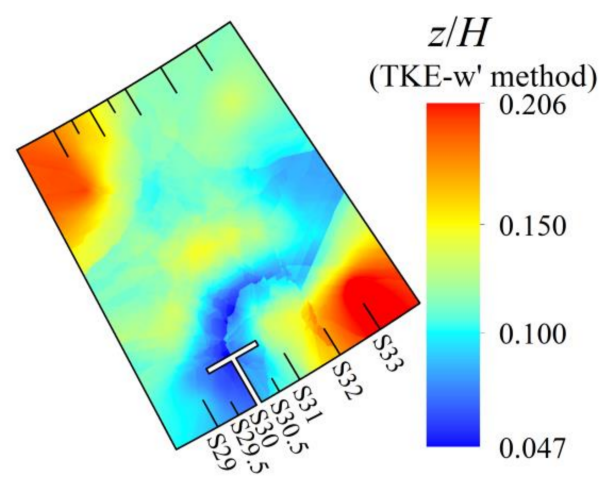

(d)

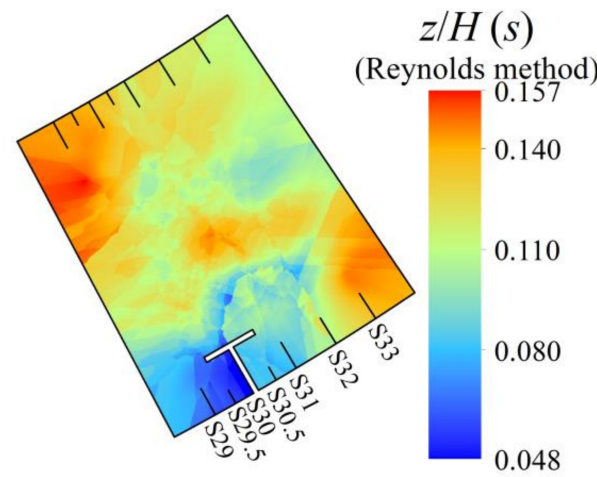

(f)

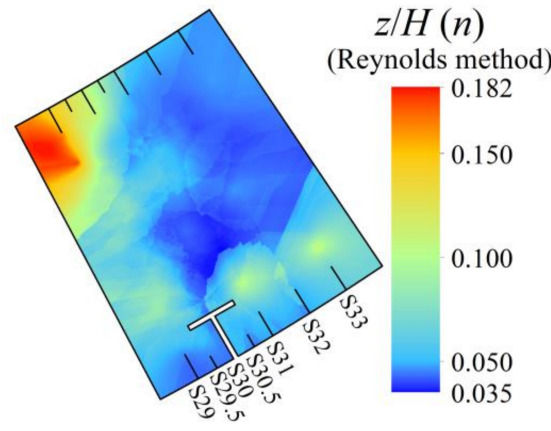

(h)

Figure 10. Peak-value heights near the groyne: $(\mathbf{a}, \mathbf{b})$ TKE method; $(\mathbf{c}, \mathbf{d})$ TKE- $\mathrm{w}^{\prime}$ method; (e,f) Reynolds method (s); (g,h) Reynolds method (n). 


\section{Conclusions}

In this study, the complex flow field in a $60^{\circ}$ bend of a river with a groyne was examined, and the bed shear stress was estimated by the turbulent energy method (TKE method), modified turbulent energy method (TKE-w' $w^{\prime}$ method), Reynolds stress method (Reynolds method), and logarithmic law (log-law method). The results are summarized as follows.

(1) It is feasible to estimate the bed shear stress in a complex flow field using velocity data for the log-law region near the bed.

(2) In this study, river bed shear stress estimates obtained using the log-law method were found to be closer to those obtained using the Reynolds method at both low and high shear stress levels than those obtained using the TKE and TKE- $w^{\prime}$ methods.

(3) If the turbulent kinetic energy method was used to calculate the bed shear stress, the experimental results showed that the TKE- $\mathrm{w}^{\prime}$ method was more suitable for bed shear stress estimation than the TKE method, but the value of its constant $C_{2}$ needed to be re-estimated.

(4) The Reynolds method and the log-law method can both be used to determine the streamwise and transverse directions of bed shear stress.

(5) In a complex, strong, three-dimensional flow field, the height of the measurement point (relative or absolute) should be re-estimated when the single point measurement is used to estimate the bed shear stress.

Author Contributions: Conceptualization, L.Z. and F.Z.; methodology, L.Z.; software, L.Z.; validation, L.Z. and F.Z.; formal analysis, L.Z.; investigation, L.Z., F.Z., A.C., Z.S. and S.T.; resources, L.Z. and F.Z.; data curation, L.Z. and F.Z.; writing-original draft preparation, L.Z.; writing-review and editing, L.Z. and F.Z.; visualization, L.Z.; supervision, F.Z.; project administration, F.Z. All authors have read and agreed to the published version of the manuscript.

Funding: This research was funded by the National Natural Science Foundation of China, grant number 51679157, the National Key Research and Development Program, grant number 2016YFC0401705, and the Sichuan Science and Technology Program, grant number 2019JDTD0007.

Acknowledgments: The authors would like to thank Wangru Wei for his helpful advice and discussion about this paper.

Conflicts of Interest: The authors declare no conflict of interest.

\section{Abbreviations}

$\begin{array}{ll}H & \text { Approaching flow depth } \\ L & \text { Groyne length }(0.1 \mathrm{~m}) \\ Q & \text { Total discharge } \\ R_{\mathrm{c}} & \text { Radius of the centerline of the bend } \\ U_{0} & \text { Velocity of the approaching flow } \\ W & \text { Cross-sectional width of the main channel } \\ d_{50} & \text { Median size of the sediment } \\ h & \text { Wing height of the groyne above the bed } \\ i & \text { Flume longitudinal slope }(0.001) \\ l & \text { The mixing length } \\ n & \text { Transverse location coordinates } \\ s & \text { Longitudinal location coordinates } \\ u, v, w & \text { Velocity of the streamwise, transverse, and vertical components } \\ u^{\prime}, v^{\prime} \text { and } w^{\prime} & \text { Velocity fluctuations of the streamwise, transverse, and vertical components } \\ \bar{u}, \bar{v} \text { and } \bar{w} & \text { Time-averaged velocity of the streamwise, transverse, and vertical components } \\ u * & \text { Friction velocity } \\ \mathrm{x}, \mathrm{y}, \mathrm{z} & \text { Rectangular Cartesian coordinates } \\ z_{\mathrm{a}} & \text { Height above the bed } \\ z_{0} & \text { Statistical roughness length } \\ v_{\mathrm{C}} & \text { Critical velocity of the sediment }\end{array}$




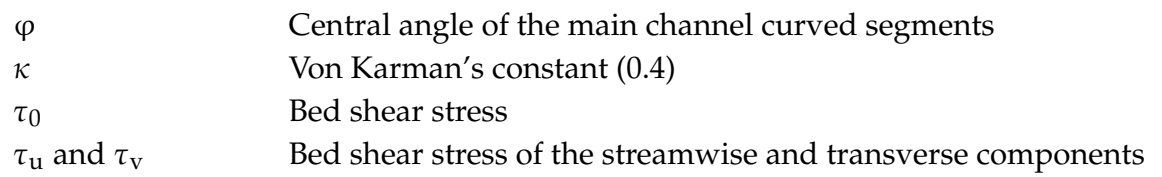

\section{References}

1. Wilcock, P.R. Estimating local bed shear stress from velocity observations. Water Resour. Res. 1996, 32, 3361-3366. [CrossRef]

2. Pujara, N.; Liu, P.L.F. Direct measurements of local bed shear stress in the presence of pressure gradients. Exp. Fluids 2014, 55. [CrossRef]

3. Kim, S.C.; Friedrichs, C.T.; Maa, J.P.Y.; Wright, L.D. Estimating bottom stress in tidal boundary layer from Acoustic Doppler Velocimeter data. J. Hydraul. Eng. ASCE 2000, 126, 399-406. [CrossRef]

4. Voulgaris, G.; Trowbridge, J.H. Evaluation of the Acoustic Doppler Velocimeter (ADV) for turbulence measurements. J. Atmos. Ocean. Technol. 1998, 15, 272-289. [CrossRef]

5. Babaeyan-Koopaei, K.; Ervine, D.A.; Carling, P.A.; Cao, Z. Velocity and turbulence measurements for two overbank flow events in River Severn. J. Hydraul. Eng. ASCE 2002, 128, 891-900. [CrossRef]

6. Nikora, V.; Goring, D. Flow turbulence over fixed and weakly mobile gravel beds. J. Hydraul. Eng. ASCE 2000, 126, 679-690. [CrossRef]

7. Chen, X.W.; Chiew, Y.M. Response of velocity and turbulence to sudden change of bed roughness in open-channel flow. J. Hydraul. Eng. ASCE 2003, 129, 35-43. [CrossRef]

8. Heathershaw, A.D. Turbulent structure of the bottom boundary-layer in a tidal current. Geophys. J. R. Astron. Soc. 1979, 58, 395-430. [CrossRef]

9. Bin Asad, S.M.S.; Lundström, T.S.; Andersson, A.G.; Hellström, J.G.I.; Leonardsson, K. Wall shear stress measurement on curve objects with PIV in connection to benthic fauna in regulated rivers. Water 2019, 11, 650. [CrossRef]

10. Hrissanthou, V.; Hartmann, S. Measurements of critical shear stress in sewers. Water Res. 1998, 32, $2035-2040$. [CrossRef]

11. Williams, J.J. Drag and sediment dispersion over sand waves. Estuar. Coast. Shelf Sci. 1995, 41, 659-687. [CrossRef]

12. Liu, C.J.; Li, D.X.; Wang, X.K. Friction velocity and velocity distribution for uniform flow in open channel. J. Hydraul. Eng. 2005, 130, 950-955. (In Chinese) [CrossRef]

13. Shivpure, V.; Sharm, A.; Kumar, B. Comparison of bed shear stress in plane and curvilinear bed channel using multiple criteria. Water Resour. 2016, 43, 79-85. [CrossRef]

14. Biron, P.M.; Robson, C.; Lapointe, M.F.; Gaskin, S.J. Comparing different methods of bed shear stress estimates in simple and complex flow fields. Earth Surf. Process. Landf. 2004, 29, 1403-1415. [CrossRef]

15. Izquierdo, U.; Esteban, G.A.; Blanco, J.M.; Albaina, I.; Peña, A. Experimental validation of a CFD model using a narrow wave flume. Appl. Ocean Res. 2019, 86, 1-12. [CrossRef]

16. Zhang, R.J. River Dynamics; Wuhan University Press: Wuhan, China, 2007.

17. Zhang, L.Y.; Zhang, F.X.; Cai, A.L.; Song, Z.M.; Tong, S.L. Application of 3D laser scanning technology in simulating river flows. Water Resour. Power 2020, 38, 121-124. (In Chinese)

18. Goring, D.G.; Nikora, V.I. Despiking Acoustic Doppler Velocimeter data. J. Hydraul. Eng. ASCE 2002, 128, 117-126. [CrossRef]

19. Poggi, D.; Porporato, A.; Ridolfi, L. Analysis of the small-scale structure of turbulence on smooth and rough walls. Phys. Fluids 2003, 15, 35-46. [CrossRef]

20. Chrisohoides, A.; Sotiropoulos, F.; Sturm, T.W. Coherent structures in flat-bed abutment flow: Computational fluid dynamics simulations and experiments. J. Hydraul. Eng. 2003, 129, 177-186. [CrossRef] 
21. Kiraga, M.; Popek, Z. Bed shear stress influence on local scour geometry properties in various flume development conditions. Water 2019, 11, 2346. [CrossRef]

22. Song, T.; Chiew, Y.M. Turbulence measurement in nonuniform open-channel flow using Acoustic Doppler Velocimeter (ADV). J. Eng. Mech. ASCE 2001, 127, 219-232. [CrossRef]

(C) 2020 by the authors. Licensee MDPI, Basel, Switzerland. This article is an open access article distributed under the terms and conditions of the Creative Commons Attribution (CC BY) license (http://creativecommons.org/licenses/by/4.0/). 